\title{
Establishment of Karadeniz Technical University Permanent GNSS Station as Reactivated of TRAB IGS Station
}

\author{
Selma Zengin Kazancı*, Emine Tanır Kayıkçı \\ Karadeniz Technical University \\ Department of Geomatics Engineering \\ 61080, Trabzon, Turkey \\ e-mails: szengin@ktu.edu.tr; etanir@ktu.edu.tr \\ * Corresponding author: Selma Zengin Kazanc1
}

Received: 17 July 2017 / Accepted: 22 September 2017

\begin{abstract}
In recent years, Global Navigation Satellite Systems (GNSS) have gained great importance in terms of the benefits it provides such as precise geodetic point positioning, determining crustal deformations, navigation, vehicle monitoring systems and meteorological applications etc. As in Turkey, for this purpose, each country has set up its own GNSS station networks like Turkish National Permanent RTK Network analyzed precise station coordinates and velocities together with the International GNSS Service, Turkish National Fundamental GPS Network and Turkish National Permanent GNSS Network (TNPGN) stations not only are utilized as precise positioning but also GNSS meteorology studies so total number of stations are increased.

This work is related to the reactivated of the TRAB IGS station which was established in Karadeniz Technical University, Department of Geomatics Engineering. Within the COST ES1206 Action (GNSS4SWEC) KTU analysis center was established and Trop-NET system developed by Geodetic Observatory Pecny (GOP, RIGTC) in order to troposphere monitoring. The project titled "Using Regional GNSS Networks to Strengthen Severe Weather Prediction" was accepted to the scientific and technological research council of Turkey (TUBITAK). With this project, we will design 2 new constructed GNSS reference station network. Using observation data of network, we will compare water vapor distribution derived by GNSS Meteorology and GNSS Tomography. At this time, KTU AC was accepted as E-GVAP Analysis Centre in December 2016. KTU reference station is aimed to be a member of the EUREF network with these studies.
\end{abstract}

Keywords: GNSS station, TRAB, IGS, EUREF.

\section{Introduction}

Global Navigation Satellite Systems (GNSS) are used ground mapping, transportation, precision agriculture, timing, unmanned vehicles, aerial photogrammetry precise geodetic point positioning, determining crustal deformations, navigation, vehicle 
monitoring systems and meteorological applications etc. GNSS have gained great improvements on the accuracy of measurement techniques. For this purpose, almost all over the world has been established GNSS reference stations.

The basic concept of GNSS reference station is to consist GNSS receiver and stable antenna. The receiver stores GNSS raw observations to FTP server and controlled by remote system. Nowadays, there are many GNSS reference station networks such as European Reference Frame (EUREF), GNSS Earth Observation Network System (GEONET), Australian Regional GNSS Network (ARGN), South Pacific Regional GNSS Network (SPRGN), AuScope Network and International GNSS Service (IGS Network) (URL 1). The analysis centers that evaluate the data in these networks are like The International GNSS Service (IGS)-USA, Centro di Geodesia Spaziale G. Colombo (ASI), Matera - Italy, Bundesamt für Kartographie und Geodäsie (BKG) - Germany, Institut Géographique National (IGN) - France, Slovak University of Technology (SUT) Slovakia, GNSS Analysis Center at Shanghai Astronomical Observatory (SHAO) - China, Geospatial Information Authority of Japan (GSI)-Japan.

The project titled "Using Regional GNSS Networks to Strengthen Severe Weather Prediction" was accepted by the scientific and technological research council of Turkey (TUBITAK) in December 2016. Therefore 3 new GNSS reference stations will established like TRAB GNSS Reference Station. The main aim of these stations is to determine of atmospheric water vapor distribution by GNSS meteorology and GNSS tomography software. In this study aim of GNSS Reference Station TRAB is explained.

\section{TRAB GNSS reference station}

According the agreement between KTU-Karadeniz Technical University (department of Geomatics Engineering, the name was department of geodesy and photogrammetry engineering at that time) and Institüt für Angewandte Geodaesie of BKG on May 22 1995, TRAB IGS station was established and operated in KTU (Trabzon) as a joint permanent station within EUREF and WEGENER arrays between 2002-2006. Both parties of KTU and BKG supported the operation of permanent GPS station. BKG part accepted to make avaliable the corresponding hardware and sorftware and perform the installation at the site in KTU (Trabzon). KTU part accepted to prepare the location for installation, and arranged the internet connection and took over the local operation of permanent GPS- station. According to this agreement both parties will contact each other in order to arrange the maintenance, the repair of the upgrading of the hard and software.

Due to the some hardware issues, old type of receiver and antenna, The receiver of TRAB got broken in November 2007. Eventhough EUREF site and some colleagues from geodesy division of KTU intended to install a new GPS+GLONASS equipment in TRAB, unfortunately authority of Karadeniz Technical University could not found a solution for import new receiver. TRAB GPS Permanent Tracking Station were closed down in January 2012. 
Finally in 2015, colleagues from geodesy division submit an proposal to Dean Office of KTU Engineering Faculty to reactivate TRAB permanent GNSS station as a newborn candidate of IGS and EUREF. With this project proposal new receiver has been installed to reactivate TRAB GNSS station by using same antenna of previous TRAB IGS station. (Figure 1). There are not any physical obstacles affecting the signal quality around the station. Spectra Precision Ashtech Proflex 800 GNSS receiver and ASH700936D_M + SNOW GNSS antenna is used on TRAB reference station. The online archive of GNSS data available through the TRAB site includes data with 15-min latency at a 30-second sampling rate for real time analysis purposes.

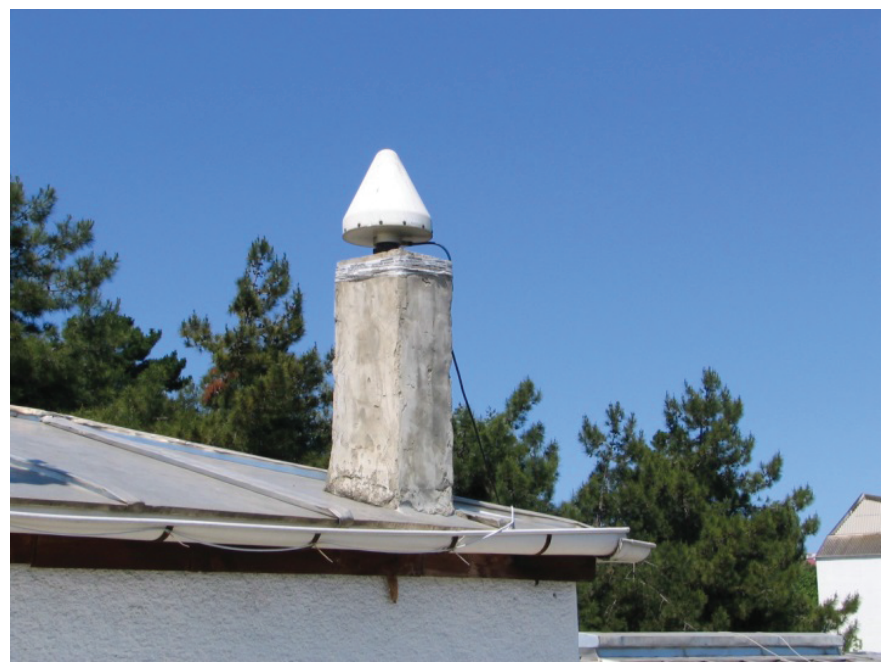

Fig. 1 TRAB GNSS Reference Station

Current TRAB Permanent GNSS station operated by KTU intend to be part of EUREF Permanent GNSS Network and IGS network.

The observed GNSS data has been stored on central FTP server will processed and analyzed continuously within some national (two TUBITAK projects) and international projects (TropNET analysis center and E-GVAP analysis center) for monitoring tropospheric products. TUTGA (Figure 2) network constitutes 147 Continuously Operating Reference Stations controlled by two control stations, the Master Control Station at the Photogrammetry and Geodesy Administration of the General Directorate of Land Registration and Cadastre and the Auxiliary Control Station at the Headquarters of the General Command of Mapping of Turkey (Yildirim et al. 2011). TRAB GNSS Reference Station was one of the 4 IGS stations (TRAB, ANKR, TUBI and ISTA) in Turkey. Reference stations at Yildiz Technical University in Istanbul (YLDZ) and Afyon Kocatepe University in Afyon (AFKU) were established in 2012 as new reference stations of GNSS Geo Sensor Network (GGNTR) in South 
West of Turkey (Gulal et al. 2014). TUBI is a continuously Operating GPS Station of Tubitak in Gebze Since 220/1999 (GPSweek No 1022).

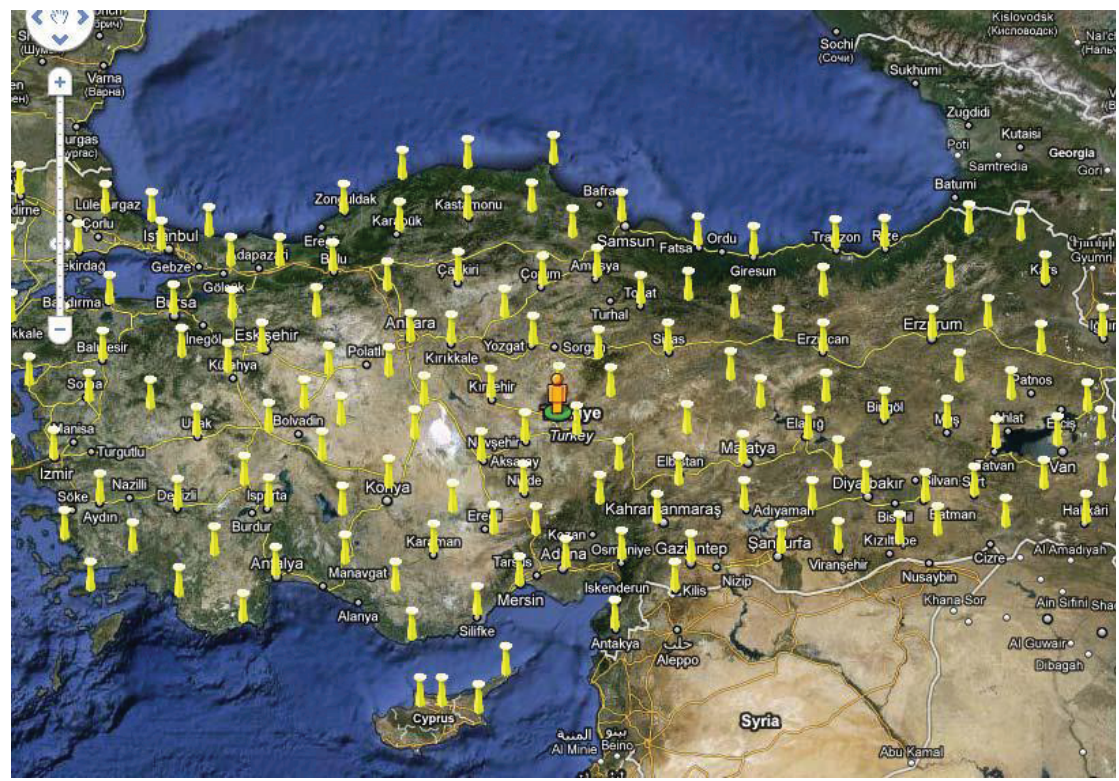

Fig. 2 TUTGA Stations (URL 2)

\section{TRAB and KTU Analysis Centre}

The GNSS derived Zenith Tropospheric Delays (ZTDs) play an important role in meteorological studies, by using ZTDs at GNSS sites into numerical weather prediction models. The Trop-NET system (reference) developed at the Geodetic Observatory Pecny (GOP, RIGTC) in order to facilitate near real-time troposphere monitoring using ground based GNSS data (based on the Bernese GNSS Software) has been installed and been routinely used in KTU AC since September 2014 (URL 2). KTU AC were established a cooperation with GOP within the COSTES1206 Action (GNSS4SWEC, WG1).

About 33 sites from IGS and EUREF permanent networks in entire Europe have been selected for an initial setting and testing (Douša 2010). Currently TropNET analysis at the KTU AC includes two IGS sites, ANKR(Ankara) and ISTA(İstanbul), from Turkey and we intend to increase the number of Turkish GNSS stations in analysis. The first attempt for this task is to include TRAB which was active only during 1047-1456 GPS weeks (2000-2007) as IGS network station.

According to hazard management data of last 20 years, Black sea Region has been affected by hydrological origin severe weather events. Moreover, according to climate change scenarios (until 2100) for future, it has been foreseen that East Black 
sea Region will be one of the region where severe weather events especially heavily rain and flood will increased related to climate change (URL 3).

This situation states a necessity of reliable weather monitoring and prediction system. The capacity of prediction and monitoring of severe weather events formation depends on accurate water vapor information (Wu et al. 2014). The project titled "Using Regional GNSS Networks to Strengthen Severe Weather Prediction" was accepted by the scientific and technological research council of Turkey (TUBITAK) in December 2016.

- To determine of atmospheric water vapor distribution by GNSS meteorology and GNSS tomography software developed by ourselves using observation data of network designed with 2 new constructed GNSS reference station. Therefore, it is targeted to perform accuracy analysis of water vapor distributions derived by GNSS meteorology and GNSS tomography.

- To compare water vapor distributions derived by GNSS tomography with those derived by rawinsonde and NWM (MM5, ALADIN, ECMWF, etc.) at dates which severe weather events recorded according to Turkish State Meteorological Service data (Figure 3).

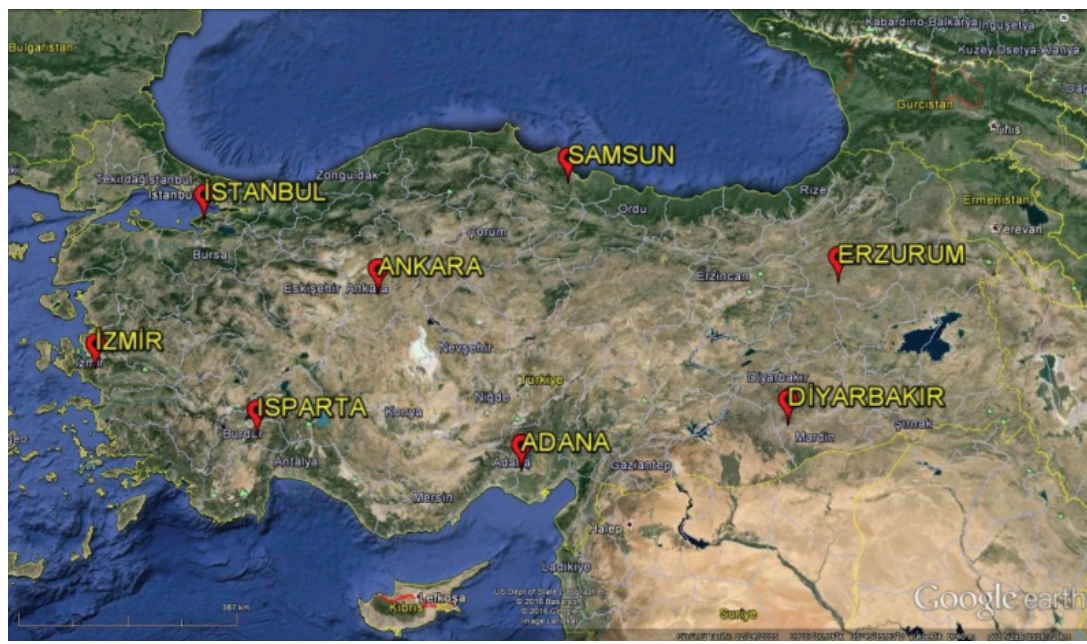

Fig. 3 Rawinsonde Stations of TURKEY

- Near real time water vapor distribution will be determined by Trop-NET (URL4) software installed at Analysis Center of Karadeniz Technical University (KTU) Department of Geomatics Engineering within a collaboration with Geodetic Observatory Pecny (Czech Republic) within COST Action ES1206 (Advanced Global Navigation Satellite Systems Tropospheric Products for Monitoring Severe Weather Events and Climate-GNSS4SWEC) to provide support The EUMETNET EIG GNSS water vapor programme (E-GVAP) and also KTU AC was accepted as E-GVAP Analysis Centre in December 2016. 
- Water vapor distribution derived with GNSS meteorology and GNSS tomography software developed by ourselves will be compared.

- It is targeted to evaluate the possible contribution of GNSS tomography to predict severe weather events by monitoring near real time water vapor distribution.

\section{Conclusions}

TRAB GNSS reference station has been operational since February 2015. Increasing number of stations including national and international networks in our country, interoperability and beneficial use of country resources will be beneficial for our country to include Karadeniz Technical University TRAB GNSS reference station in EUREF / IGS networks. Since the location and type of antennas have not changed in order to be included in EUREF / IGS networks, it is estimated that the existing station can be replaced with the same 4 character abbreviation. KTU reference station is aimed to be a member of the EUREF / IGS networks with these studies.

\section{Acknowledgements}

This study is funded by the Scientific and Technological Research Council of Turkey (TUBITAK) for the project entitled "Using Regional GNSS Networks to Strengthen Severe Weather Prediction" (Project No: 116Y186).

\section{References}

Douša, J. (2010). Precise near real-time GNSS analyses at Geodetic observatory Pecný - precise orbit determination and water vapour monitoring, Acta Geodyn Geomater, 7, 1 (157), 1-11. http://www. irsm.cas.cz/materialy/acta_content/2010_01/2_Dousa.pdf

Gülal E., Dindar A. A., Akpınar B., Tiryakioğlu I, Aykut N. O., and Erdoğan H. (2015). Analysis and Management of GNSS Reference Station Data, Tehnički Vjesnik, 22, 2(2015), 407-414, DOI: 10.17559/TV- 20140717125413.

URL 1. Accessed 7 May 2017 http://www.ga.gov.au/scientific-topics/positioning-navigation/geodesy/ gnss-networks

URL 2. Accessed 10 May 2017 http://cors-tr.iku.edu.tr/en_corstr_projeozetigenel.htm

URL 3. Accessed 1 July 2017 http://www.mgm.gov.tr/FILES/iklim/iklim-degisikligi-projeksiyon2015.pdf

URL 4. Accessed 2 July 2017 http://www.pecny.cz/gop/index.php/trop-net

Yildirim, Ö., Salgin, Ö., and Bakici, S. (2011). The Turkish CORS Network (TUSAGA-Aktif), TS03G - GNSS CORS Networks Case Studies (Flash), FIG Working Week 2011, Bridging the Gap between Cultures Marrakech, Morocco, 18-22 May 2011.

Wu S., Manning T., Yuan Y., Wang X., Kealy A., Marshall J., and Zhang K. (2014). Strengthening Severe Weather Prediction Using the Advanced Victorian Regional GPS Network - a Recent NDRGS Project, Geospatial Science Research 3. School of Mathematical and Geospatial Science, RMIT University. 